\title{
Conglutinin - an Important Element of Natural Immunity in Ruminants (a Review)
}

\author{
Joanna Śliwa-Dominiak, Beata Tokarz-Deptuła, Paulina Niedźwiedzka-Rystwej, \\ Wiesław Deptuła
}

Department of Microbiology and Immunology, Faculty of Natural Science, University of Szczecin, Poland

Received November 18, 2008

Accepted September 8, 2009

\begin{abstract}
Conglutinin represents a collectin appearing only in some mammals, including cattle. It plays an important role in resistance of hosts against microbes and parasites. It exhibits affinity toward saccharides present on the surface of bacteria, viruses, fungi and parasites and it mobilizes the mechanisms leading to their inactivation. It manifests also the unique ability of agglutinating complement- and antibody-coated erythrocytes. Moreover, it shows the ability to activate immune system cells, including the process of phagocytosis. In this review also the factors that determine the amount and activity of conglutinin in mammalian serum were presented, including environmental conditions and infectious agents, such as various types of bacteria and viruses. The broad scope of conglutinin is genetically controlled and, therefore, this collectin may constitute a useful and crucial factor in cattle husbandry
\end{abstract}

Conglutinin, collectin, inborn immunity, animals, cattle, conglutination, anti-microbial activity

Conglutinin represents the first protein in the group of present collectins, detected in cattle serum by Ehrlich and Sachs in 1902 and by Bordet in 1909, participating in the reaction termed conglutination (agglutination of complement-coated erythrocytes) (Ingram and Barnum 1965). The phenomenon was registered and reported in cases of bacteria-infected cattle (Ingram and Mitchell 1971), including cattle infected with Mycobacterium bovis (Holmskov et al. 1998), in which decreased agglutinating activity was described. Conglutinin is accepted to represent an important element of non-specific humoral immunity, at present termed the inborn immunity, found only in some ruminants of the Bovidae family (Koch et al. 2001; Thiel et al. 2006). The substance was demonstrated to exhibit anti-microbial properties: a mutation present in genes coding protein was found to increase propensity of the animals to bacterial, viral, fungal and parasitic infections (Koch et al. 2001; Thiel et al. 2006). Its anti-microbial and anti-parasitic role has been linked to its affinity to saccharides present on the surface of microbes and parasites (Lachmann 1962; $\mathrm{Lu}$ 1997). The reaction leads to activation of complement which, together with binding of the immobilised complement by specific receptors on phagocytic cells, stimulates the process of phagocytosis (Lu 1997).

\section{Structure of conglutinin}

Conglutinin is a protein of around 100 to over $1000 \mathrm{kDa}$ molecular weight (Hansen and Holmskov 1998). Its principal functional form ensuring its appropriate activity involves a trimer (Dec and Wernicki 2006). In various collectins the number of trimeric subunits may vary but conglutinin contains four trimeric subunits (Hansen et al. 2002). In each monomeric subunit of collectins the N-terminal cysteine-rich domain, the collagen-like domain and the $\alpha$-helical neck domain plus C-type lectin domain can be distinguished, the latter termed also CRD (carbohydrate-recognition domain) (Eda et al. 1996; van der Wetering et al. 2004). Every trimer consisting of monomers is stabilised by intermonomer covalent disulphide bridges, binding cystein residues in $\mathrm{N}$-terminals or in collagen

Address for correspondence:

Joanna Śliwa-Dominiak

Department of Microbiology and Immunology

Faculty of Natural Science, University of Szczecin

Felczaka 3c, 71 - 412 Szczecin, Poland
Phone: +48 91 444-16-05

Fax: +48 91 444-16-06

E-mail: Joanna.Sliwaa@gmail.com

http://www.vfu.cz/acta-vet/actavet.htm 
domains as well as by non-covalent interactions (Hoppe and Reid 1994). Moreover, in microscopical images the tetrameric molecule of conglutinin with two globular heads was found to be linked to the core by four elongated collagen branches (Andersen et al. 1992). The entire molecule contains 351 amino acid residues, including 55 Gly-X-Y repetitions with two intervals and the diameter of its tetramers is $96 \mathrm{~nm}$ (Lachmann 1967; Lee et al. 1991; Andersen et al. 1992; Hansen et al. 2002). The long collagen-like domains of the protein are separated by short $\mathrm{NH}_{2}$-terminal regions, consisting of 25 residues, originating from the long (155 residues) globular COOH terminus (Lachmann 1967; Lee et al. 1991; Hansen et al. 2002). Structural analysis of conglutinin demonstrated that its structure contains also 7 cystein residues, capable of forming inter- and/or intra-chain disulphide bridges (Lachmann 1967; Hansen et al. 2002). Two of the residues are present in the non-collagenous N-terminal segment (residues 15 and 20), four in the non-collagenous $\mathrm{COOH}$-terminal segment (residues 255, 327, 341 and 349) and one of them is present in the collagenous domain (residue 38) (Lee et al. 1991). In electron microscope the conglutinin molecule resembles in shape the letter X (Andersen et al. 1992; Lu et al. 1993).

\section{Localization of biosynthesis sites and occurrence of conglutinin}

The conglutinin-coding genes were found to be located in the chromosome 28 of cattle, at the q1.8 position (Gallagher et al. 1993; Liou et al. 1994; Hansen et al. 2002, Hansen et al. 2003), although the protein could also derive from collectin representing the SP-D, the surfactant protein $\mathrm{D}$, which represents a sequel of total or partial duplication of primordial $S P-D$ gene that occurred following divergence of the Bovidae family from other mammals (Lim et al. 1993; Holmskov 2000; Hansen et al. 2003). The hypothesis was confirmed by $78 \%$ identity of amino acid sequence between cattle collectins in the form of SP-D on one hand and conglutinin on the other (Lim et al. 1993). Presence of conglutinin was detected only in ruminants, such as cattle, dromedary, Kobus ellipsiprymnus, kobus from Uganda, kobus from Kenia, dikdik antelope (Madoqua saltiana), Damaliscus lunatus, hartebeest (Alcelaphus buselaphus), in which titre of conglutinin is particularly high (Kakoma and Kinyanjuni 1974; Dec and Wernicki 2006). Conglutinin is present in their serum, neutrophils, follicular dentritic cells, macrophages originating from liver, lungs and spleen, in thymus, lymph nodes and tonsils (Holmskov et al. 1992; Lim et al. 1993; Lu et al. 1993; Han sen et al. 2002). The localization indicates that conglutinin plays an important role in the immune system, particularly because of its ability to direct the binding of saccharide residues on the surface of microbes which promotes phagocytosis and antigen presentation (Holmskov et al. 1992).

\section{Biological properties of conglutinin}

This biologically very specific protein represents a heat-stable beta-globulin, synthesized by cells of the immune system, i.e., by neutrophils (Deptuła et al. 2008), but also and probably in prevailing amounts by hepatocytes ( $\mathrm{Lu}$ et al. 1993). Its unique property of agglutinating erythrocytes pre-incubated with antibodies and complement (Strang et al. 1986; Holmskov et al. 1992; Lu et al. 1993; Laursen et al. 1994, Dec and Wernicki 2006), depends on the presence of calcium and serum conglutinin activity factor (CAF), termed also the factor I (Eda et al. 1996). The factor splits C3b component of the complement, forming an inactive iC3b factor, which opsonizes erythrocytes (Strang et al. 1986; Hartley et al. 1992; Wakamiya et al. 1992; Hartshorn et al. 1993; Laursen et al 1994). Long-term incubation of antibody-coated erythrocytes with serum, preceded by incubation with conglutinin, abrogates the agglutinating properties (Laursen et al. 1994), due to the splitting of iC3b to C3d and C3c (Lin s cott et al. 1978; Ros s et al. 1982; Laursen et al. 1994). Binding of conglutinin to $\mathrm{iC} 3 \mathrm{~b}$ was demonstrated to be calcium-dependent but 
may also be inhibited by monosaccharides, of which N-acetyl-D-glucosamine (GlcNAc) exerts a particularly strong effect (Laursen et al. 1994). Conglutinin demonstrates also affinity to oligosaccharides in the $\alpha$ chain of $\mathrm{iC} 3 \mathrm{~b}$ ( $\mathrm{Lu}$ et al. 1993; Laursen et al. 1994), and manifests capacity to bind $\mathrm{N}$-acetylglucosamine, mannose and fructose residues (Lee et al. 1991). In vitro, the protein was found to opsonize Salmonella typhimurium and Escherichia coli (Holmskov et al. 1998), although the ability was dependent on the presence of an intact complement system and, hence, serum devoid of CAF did not promote the reaction (Holmskov et al. 1998). Studies of Friis-Christiansen et al. (1990) showed that conglutinin binding $\mathrm{iC} 3 \mathrm{~b}$ localized on bacterial surface caused that also bacteria coated in this way "cooperated" with macrophages (Holmskov et al. 1998).

\section{Conditions which affect the amount and activity of conglutinin in mammals}

The amount of conglutinin in serum of cows reflects several conditions, including environmental and infectious variables (Ingram and Barnum 1965; Ingram and Mitchell 1970; Ingram and Mitchell 1971; Du Plessis 1985; Krogh-Meibom et al. 2004; van der Wetering et al. 2004; Thiel et al. 2006). In the serum of adult individuals (studies conducted mainly on Holstein cows), its titre reached the value of 0 to 5120 (Ingram and Barnum 1965, Thiel et al. 2006). Such broad range of conglutinin concentrations in serum is genetically conditioned (Holmskov et al. 1998). Therefore, it is assumed that high inheritance of conglutinin concentrations provides a valuable and significant index, which is also taken into account in cattle husbandry since estimation of the content allows selecting individuals with higher resistance to diseases (Holmskov et al. 1998). Serum of newly born calves contains no conglutinin until the moment of colostrum administration (Ingram and Barnum 1965; Ingram and Mitchell 1970). Following the first administration of colostrum, the amount of conglutinin increases until the $20^{\text {th }}$ month of life, i.e., until the concentration is attained that is present in adult cattle (Ingram and Barnum 1965; Ingram and Mitchell 1970). The concentration was also found to depend on the sex and breed of cattle (Holmskov et al. 1998). Also the season of the year and environmental/feeding conditions were found to affect the concentration of conglutinin (Ingram and Barnum 1965; van der Wetering et al. 2004): low amount of conglutinin was observed in late winter and in spring, its high level could be detected in fall and early winter. A very marked increase in its concentration in serum could be noted within few weeks after the first pasture in the field. The high serum concentration of conglutinin in the animals was also found to reflect environmental temperatures and intensity of day light (Ingram and Barnum 1965), but the concentration was not affected by physiological rhythms (Krogh-Meibom et al. 2004). Conglutinin concentration was also strongly affected by pregnancy and abortion due to infections (Ingram and Barnum 1965; Ingram and Mitchell 1970; Ingram and Mitchell 1971). A clear-cut decrease in serum conglutinins in cows developed shortly before calving, starting at 4 weeks before term and persisting up to 2 weeks after delivery. Later, the level rapidly increased reaching high concentrations in approximately the $21^{\text {st }}$ week after delivery (Ingram and Mitchell 1970). It was concluded that the situation is linked to sex hormones and/or corticosteroids (Ingram and Mitchell 1971). A decrease in conglutinin titre was recorded in the week of abortion or between the $2^{\text {nd }}$ and $4^{\text {th }}$ week after abortion, when no conglutinins were observed in serum (Ingram and Mitchell 1971).

\section{Activity of conglutinin}

The abortions due to infections and such inflammatory conditions as pneumonia, metritis or acute infections reduce titre and activity of conglutinin in calf serum (Ingram and Mitchell 1971). An important decrease in conglutinin titre developed already one week 
before other morbid signs and persisted for 1-2 weeks after the infection took place (Ingram and Mitchell 1971a). The lowered conglutinin titres were recorded also in cows experimentally infected with Cowdria ruminantium or infected with Anaplasma marginalne (Rose et al. 1978; Du Plessis 1985). It was suggested (Dec and Wernicki 2006) that the reason for decreased conglutinin titres may involve marked hyperthermia, recorded in the infected cattle even if the probable cause of the decrease, mainly in the course of acute infections, may involve absorption of conglutinin from the serum by the activated complement component iC3b or a direct effect of microbial activity. Such conditions may arise also due to decreased activation thresholds of expression mechanisms of appropriate genes (Ingram and Mitchell 1971). Local infections, e.g., benign inflammation of mammary glands or contagious infection of hoofs (whitlow) in cattle do not considerably affect serum conglutinin amount (Ingram and Mitchell 1970). Also, no changes in their amount were noted in cattle in the course of lymphosarcoma (Ingram and Mitchell 1971). Nevertheless, experimental bacterial infections demonstrated that conglutinin remains an important variable in the infections, as noted already in 1959 by Ingram (1959). The author recorded reciprocal relationships between conglutinating activity of animal serum and experimentally induced bacterial infections. He found that pretreatment of mice with conglutinin secured higher proportions of surviving mice following their infection with virulent strains of Salmonella typhimurium, Pasteurella septica, Klebsiella pneumoniae, Listeria monocytogenes and Streptococcus pyogenes (Ingram 1959). Moreover, it was noted that infection of the mice with Salmonella typhimurium resulted in an almost immediate reduction in amounts of conglutinins in serum, which could not be documented in experimental animals infected with pathogenic and non-pathogenic strains of E. coli (Ingram 1959a). Results of the studies related to Salmonella are consistent with those originating from studies in the 1990s (Friis-Christiansen 1990), in which mice subcutaneously injected with conglutinin manifested extended survival following intraperitoneal injection of a highly virulent strain of $S$. typhimurium. Moreover, the animals manifested considerably reduced numbers of bacteria in blood in comparison to control animals administered saline (Friis-Christiansen 1990). The authors demonstrated that the anti-bacterial activity of conglutinin directed to Salmonella typhimurium was preconditioned not only by the presence of the complement system but also macrophages. They hypothesized that, binding to bacterial surface anchored $\mathrm{iC} 3 \mathrm{~b}$, conglutinin acts as a ligand mediating contact between the bacteria and the cells. They also suggested that activation of macrophages is probably linked to a mechanism of conglutinin stimulating special receptors of the cell surface which result in formation of oxygen metabolites in the cells and in this way it induces their anti-microbial activity (Friis-Christiansen 1990).

Conglutinin was also found to exhibit anti-viral activity: its activity which inhibits virallyinduced haemagglutination due to aggregation of viruses abolishes infectivity of the viruses, which has been registered in the case of group A influenza viruses, subtypes H1, H2 and H3 (Hartley et al 1992; Wakamiya et al. 1992; Hartshorn et al. 1993). Due to its lectin properties, the collectin neutralizes also other viruses (Eda et al. 1996). The latter property was documented toward rotaviruses, the VP7 protein which was bound by lectin domains of conglutinin (Ramig 2004). Such a binding results in inhibited haemagglutination by rotaviruses and in abolished infectivity of the viruses, which, as claimed by Reading et al. (1998), also depends on glycosylation of VP7 protein. This was shown studying in vitro the anti-viral activity of conglutinins directed toward bovine rotavirus NCDV (Nebraska calf diarrhoea virus), demonstrating that the protein neutralised the rotavirus by binding its VP7 glycoprotein through lectin domains of conglutinin. The potential of conglutinin was also demonstrated to bind Herpes simplex type 2 (HSV2) viruses in presence of calcium ions (Fisher et al. 1994). In those studies the protein was administered to mice before vaccine in order to protect against infection with Herpes virus, accentuated viral replication indicating 
that the vaccine provided another place for the virus to penetrate host cells (Fisher et al. 1994). In other studies (Rose et al. 1978) binding of conglutinin with HSV2 virus did not neutralize infectivity of the virus. Binding of conglutinin was demonstrated also in the case of HIV: in presence of calcium ions conglutinin bound glycoprotein 160 of the viral envelope although the reaction was noted to be inhibited by $\mathrm{N}$-acetyl-D-glucosamine and by deglycosylation of the viral gp160 protein (Andersen et al. 1991). Results of the studies demonstrated also that conglutinin may inhibit infections with HIV by blockade of interactions between CD4+ cells and the virus (Andersen et al. 1991).

It seems also interesting that no reasons are known for the absence of conglutinin in the sera of other herbivorous animals than ruminants, e.g. in the sera of horses that also live in symbiosis with enormous numbers of bacteria present in their caecum. No conglutinin could be detected in the sera of mice, rabbits, guinea pigs, cats, dogs, pigs (Rose et al. 1978), although its small amounts were noted in the sera of humans and rats, even if it was not purified and characterised (Lachmann 1967; Holmskov 1992).

\section{Conclusion}

Independently of the latter facts, conglutinin can be concluded to represent an important factor of non-specific humoral or innate immunity in animals of Bovidae family. It participates in immune processes allowing protecting hosts from various pathogens, including bacteria and viruses and, manifesting capacity to aggregate and neutralize viruses, promoting activation of the immune system including phagocytosis.

\section{References}

Andersen O, Nielsen EH, Storgaard P, Hojrup P, Friis P, Leslie G, Svehag SE 1992: Biochemical and ultrastructural studies of the C-type lectin bovine conglutinin. J Struct Biol 109: 201-207

Andersen O, Sorensen AM, Svehag SE, Fenouillet E 1991: Conglutinin binds the HIV-1 envelope glycoprotein gp160 and inhibits its interaction with cell membrane CD4. Scand J Immunol 33: 81-88

Dec M, Wernicki A 2006: Conglutinin, CL-43 and CL-46 - three bovine collectins. Pol J Vet Sci 9: 265-275

Deptuła W, Stosik M, Tokarz - Deptuła B 2008 Immunology for biologists. Academic Press, Szczecin (Poland)

Du Plessis JL 1985: The natural resistance of cattle to artificial infection with Cowdria ruminantium: the role played by conglutinin. Onderspoort J Vet Res 52: 273-277

Eda S, Suzuki Y, Kase T, Kawai T, Ohtani K, Sakamoto T, Kurimura T, Wakamiya N 1996: Recombinant bovine conglutinin, lacking the N-terminal and collagenous domains, has less conglutination activity but is able to inhibit haemagglutination by influenza A virus. Biochem J 316: 43-48

Fisher PB, Ellermann-Eriksen S, Thiel S, Jensenius JC, Mogensen SC 1994: Mannan-binding protein and bovine conglutinin mediate enhancement of Herpes Simplex virus type 2 infection in mice. Scand J Immunol 39 : 439-445

Friis-Christiansen P, Thiel S, Svehag SE, Dessau R, Svendsen P, Andersen O, Laursen SB, Jensienius JC 1990: In vivo and in vitro antibacterial activity of conglutinin, a mammalian plasma lectin. Scand J Immunol 31: 453-460

Gallagher DS Jr, Ryan AM, Liou LS, Sastry KN, Womack JE 1993: Somatic cell mapping of conglutinin (CGN1) to cattle syntetic group U29 and fluorescence in situ localization to Chromosome 28. Mamm Genome 4: 716-719

Hansen S, Holmskov U 1998: Structural aspects of collectins and receptors for collectins. Immunobiology 199: 165-189

Hansen S, Holm D, Moeller V, Vitved L, Bendixen C, Reid KB, Skjoedt K, Holmskov U 2002: CL-46, a novel collectin highly expressed in bovine thymus and liver. J Immunol 169: 5726-5734

Hansen S, Holm D, Moeller V, Vitved L, Bendixen C, Skjoedt K, Holmskov U 2003: Genomic and molecular characterization of CL-43 and its proximal promoter. Biochim Biophys Acta 1625: 1-10

Hartley CA, Jackson DC, Anders EM 1992: Two distinct serum mannose-binding lectins function as beta inhibitors of influenza virus: identification of bovine serum beta inhibitor as conglutinin. J Virol 66: 4358-4363

Hartshorn KL, Sastry K, Brown D, White MR, Okarma TB, Lee YM, Tauber AI 1993: Conglutinin acts as an opsonin for influenza A viruses. J Immunol 151: 6265-6273

Holmskov U, Jensenius JC, Tornoe I, Lovendahl P 1998: The plasma levels of conglutinin are heritable in cattle and low levels predispose to infection. Immunology 93: 431-436

Holmskov U, Teisner B, Pedersen NT, Laursen SB, Rasmussen HB, Jensenius JC 1992: Tissue localization of conglutinin, a bovine C-type lectin. Immunology 76: 169-173 
Holmskov UL 2000: Collectin and collectin receptors in innate immunity. APMIS Suppl 100: 1-59

Hoppe HJ, Reid KB 1994: Collectins-soluble proteins containing collagenous regions and lectin domains - and their roles innate immunity. Protein Sci 3: 1143-1158

Ingram DG, Barnum DA 1965: Fluctuations in the level of conglutinin in bovine serum. Can Vet J 6: 162-169

Ingram DG, Mitchell WR 1970: Conglutinin levels in dairy cattle: changes associated with parturition. Am J Vet Res 31: 487-492

Ingram DG 1959: The conglutination phenomenon. XIII. In vivo interactions of conglutinin and experimental bacterial infection. Immunology 2: 322-333

Ingram DG 1959a: The conglutination phenomenon. XIV. The resistance enhancing effect of conglutinin and and immuno-conglutinin in experimental bacterial infections. Immunology 2: 334-345

Ingram DG, Mitchell WR 1971: Conglutinin level in dairy cattle: changes associated with diseases. Am J Vet Res 32: $875-878$

Ingram DG, Mitchell WR 1971a: Conglutinin levels in dairy cattle: seasonal fluctuations. Am J Vet Res 32: 23-28

Kakoma I, Kinyanjuni M 1974: The effect of breed and age on the distribution of conglutinin and immunoconglutinin in normal cattle. Res Vet Sci 17: 122-124

Koch A, Melbye M, Sorensen P, Homoe P, Madsen HO, Molbak K, Hansen CH, Andersen LH, Hahn GW, Garred P 2001: Acute respiratory tract infections and mannose-binding lectin insufficiency during early childhood. JAMA 285: 1316-1321

Krogh-Meibom T, Holmskov U,Lovendahl P, Nielsen NI, Ingvartsen KL2004:A time-resolved immunofluorometric assay for quantification of the bovine collectin conglutinin. J Immunol Methods 286: 87-96

Lachmann PJ 1962: A comparison of some properties of bovine conglutinin with those of rabbit immunoconglutinin. Immunology 5: 687-705

Lachmann PJ 1967: Conglutinin and immunoconglutinins. Adv Immunol 6: 479-527

Laursen SB, Thiel S, Teisner B, Holmskov U, Wang Y, Sim RB, Jensenius JC.1994: Bovine conglutinin binds to an oligosaccharide determinant presented by iC3b, but not by $\mathrm{C} 3, \mathrm{C} 3 \mathrm{~b}$ or $\mathrm{C} 3 \mathrm{c}$. Immunology 81: 648-654

Lee YM, Leiby KR, Allar J, Paris K, Lerch B, Okarma TB 1991: Primary structure of bovine conglutinin, a member of the C-type animal lectin family. J Biol Chem 266: 2715-2723

Lim BL, Lu J, Reid KB 1993: Structural similarity between bovine conglutinin and bovine lung surfactant protein $\mathrm{D}$ and demonstration of liver as a site of synthesis of conglutinin. Immunology 78: 159-165

Linscott WD, Ranken R, Triglia RP 1978: Evidence that bovine conglutinin reacts with an early product of C3b degradation, and an improved conglutination assay. J Immunol 121: 658-664

Liou LS, Sastry R, Hartshorn KL, Lee YM, Okarma TB, Tauber AI, Sastry KN 1994: Bovine conglutinin (BC) mRNA expressed in liver: cloning and characterization of the BC cDNA reveals strong homology to surfactant protein-D. Gene 141: 277-281

Lu J, Laursen SB, Thiel S, Jensenius JC, Reid KB 1993: The cDNA cloning of conglutinin and identification of liver as a primary site of synthesis of conglutinin in members of the Bovidae. Biochem J 292: 157-162

Lu J 1997: Collectins: collectors of microorganisms for the innate immune system. BioEssays 19: 509-518

Ramig RF 2004: Pathogenesis of intestinal and systemic rotavirus infection. J Virol 78: 10213-10220

Reading PC, Holmskov U, Anders EM 1998: Antiviral activity of bovine collectins against rotaviruses. J Gen Virol 79: 2255-2263

Rose JE, Amerault TE, Roby TO, Martin WH 1978: Serum levels of conglutinin, complement, and immunoconglutinin in cattle infected with Anaplasma marginale. Am J Vet Res 39: 791-793

Ross GD, Lambris JD, Cain JA, Newman SL 1982: Generation of three different fragments of bound C3 with purified factor I or serum. I. Requirements for factor $\mathrm{H}$ vs Cr1 cofactor activity. J Immunol 129: 2051-2060

Strang CJ, Slayter HS, Lachmann PJ, Davis AE 3rd 1986: Ultrastructure and composition of bovine conglutinin. Biochem J 234: 381-389

Thiel S, Frederiksen PD, Jensenius JC 2006: Clinical manifestations of mannan-binding lectin deficiency. Mol Immunol 43: 86-96

van der Wetering JK, van Golde LM, Batenburg JJ 2004: Collectins: players of the innate immune system. Eur J Biochem 271: 1229-1249

Wakamiya N, Okuno Y, Sasao F, Ueda S, Yoshimatsu K, Naiki M, Kurimura T 1992: Isolation and characterization of conglutinin as an influenza A virus inhibitor. Biochem Biophys Res Commun 187: 1270-1278 